\title{
Initial in-hospital heart rate is associated with long-term survival in patients with acute ischemic stroke
}

\author{
Jiann-Der Lee ${ }^{1} \oplus \cdot{\text { Ya-Wen } \mathrm{Kuo}^{2} \cdot \text { Chuan-Pin Lee }^{3} \cdot \text { Yen-Chu Huang }}^{1} \cdot$ Meng Lee $^{1} \cdot$ Tsong-Hai Lee $^{4}$
}

Received: 21 July 2021 / Accepted: 13 October 2021 / Published online: 23 October 2021

(c) The Author(s) 2021

\begin{abstract}
Aims Increased heart rate has been associated with stroke risk and outcomes. The purpose of this study was to explore the long-term prognostic value of initial in-hospital heart rate in patients with acute ischemic stroke (AIS).

Methods We analyzed data from 21,655 patients with AIS enrolled (January 2010-September 2018) in the Chang Gung Research Database. Mean initial in-hospital heart rates were averaged and categorized into 10-beat-per-minute (bpm) increments. The primary and secondary outcomes were all-cause mortality and cardiovascular death. Hazard ratios (HRs) and 95\% confidence intervals (CIs) were estimated using multivariable adjusted Cox proportional hazard models, using the heart rate $<60 \mathrm{bpm}$ subgroup as the reference.

Results The adjusted HRs for all-cause mortality were 1.23 (95\% CI 1.08-1.41) for heart rate 60-69 bpm, 1.74 (95\% CI 1.531.97) for heart rate 70-79 bpm, 2.16 (95\% CI 1.89-2.46) for heart rate 80-89 bpm, and 2.83 (95\% CI 2.46-3.25) for heart rate $\geq 90 \mathrm{bpm}$ compared with the reference group. Likewise, heart rate $\geq 60 \mathrm{bpm}$ was also associated with an increased risk of cardiovascular death (adjusted HR 1.18 [95\% CI 0.95-1.46] for heart rate 60-69 bpm, 1.57 [95\% CI 1.28-1.93] for heart rate 70-79 bpm, 1.98 [95\% CI 1.60-2.45] for heart rate 80-89 bpm, and 2.36 [95\% CI 1.89-2.95] for heart rate $\geq 90 \mathrm{bpm}$ ). Conclusions High initial in-hospital heart rate is an independent predictor of all-cause mortality and cardiovascular death in patients with AIS.
\end{abstract}

Tsong-Hai Lee

thlee@adm.cgmh.org.tw

1 Department of Neurology, Chiayi Chang Gung Memorial Hospital, Chiayi, and College of Medicine, Chang Gung University, Taoyuan, Taiwan

2 Department of Nursing, Chang Gung University of Science and Technology, Chiayi Campus, Chiayi, Taiwan

3 Health Information and Epidemiology Laboratory, Chang Gung Memorial Hospital, Chiayi, Taiwan

4 Department of Neurology, Linkou Chang Gung Memorial Hospital, Taoyuan, and College of Medicine, Chang Gung University, Taoyuan, Taiwan 


\section{Graphical abstract}

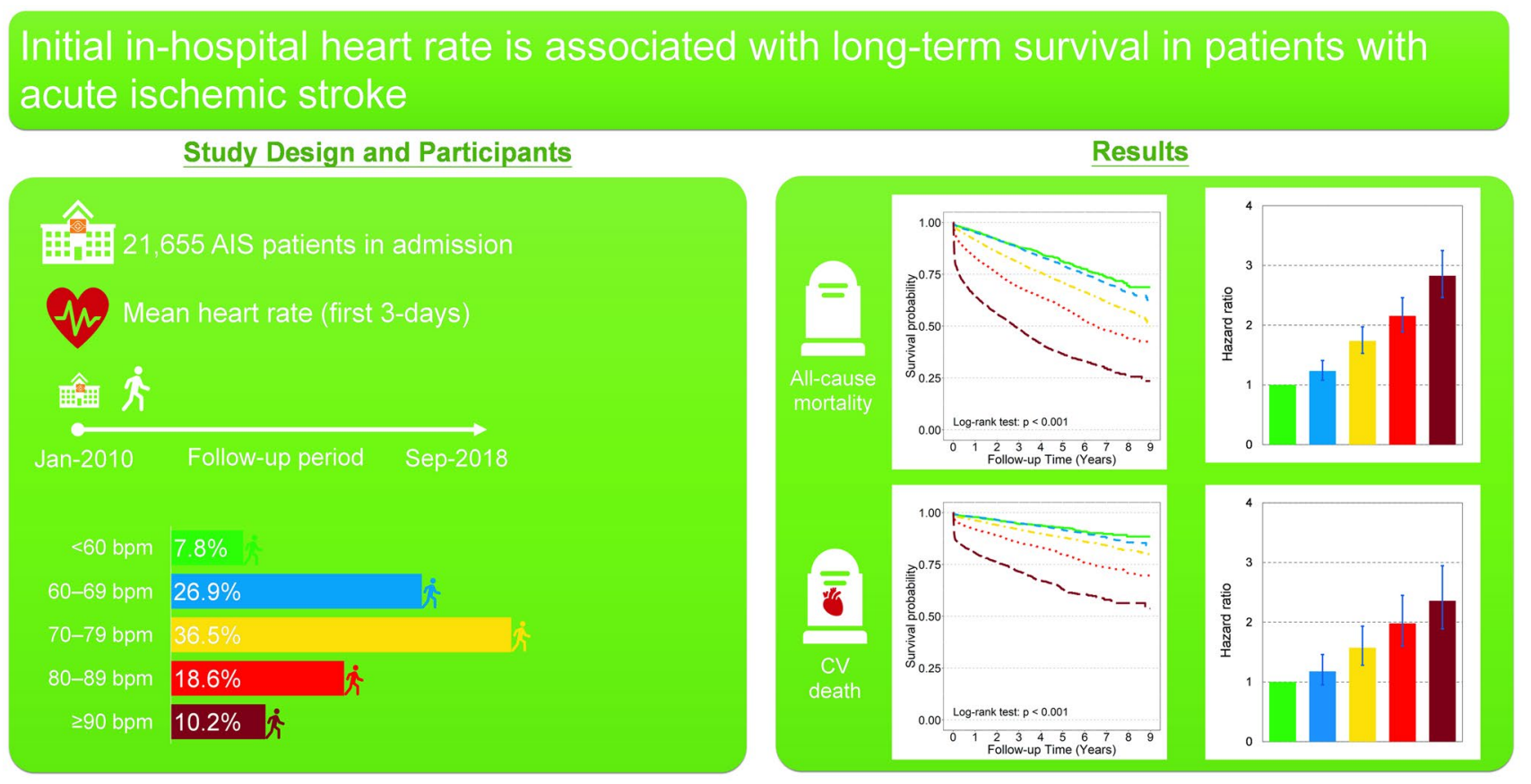

Keywords Heart rate $\cdot$ Acute ischemic stroke $\cdot$ Mortality $\cdot$ Survival

$\begin{array}{ll}\text { Abbreviations } \\ \text { bpm } & \text { Beats per minute } \\ \text { AIS } & \text { Acute ischemic stroke } \\ \text { ICD-10 } & \text { International Classification of Diseases, 10th } \\ & \text { Revision, Clinical Modification } \\ \text { SSI } & \text { Stroke severity index } \\ \text { eNIHSS } & \text { Estimated National Institutes of Health Stroke } \\ & \text { Scale } \\ \text { SBP } & \text { Systolic blood pressure } \\ \text { DBP } & \text { Diastolic blood pressure } \\ \text { ALT } & \text { Alanine aminotransferase } \\ \text { HbA1c } & \text { Glycated hemoglobin } \\ \text { eGFR } & \text { Estimated glomerular filtration rate } \\ \text { CKD } & \text { Chronic kidney disease } \\ \text { CI } & \text { Confidence interval } \\ \text { HTN } & \text { Hypertension } \\ \text { DM } & \text { Diabetes mellitus } \\ \text { AF } & \text { Atrial fibrillation } \\ \text { CHF } & \text { Congestive heart failure } \\ \text { TG } & \text { Triglyceride } \\ \text { BMI } & \text { Body mass index }\end{array}$

\section{Introduction}

Despite improvements in secondary prevention treatment, the incidence rates of mortality and recurrent cardiovascular events post-stroke remain high [1-3]. This indicates that many risk factors have yet to be identified.

A slower heart rate is associated with greater longevity in many mammal species [4]. Heart rate is a vital sign which varies according to the physical needs of the body. Heart rate also reflects the balance between sympathetic and parasympathetic tone to the heart, and it has been shown to be a predictor of cardiovascular and all-cause mortality in the general population and in patients with cardiovascular disease [5-12]. In a review article of 18 epidemiological studies, Aboyans and Criqui reported an increase in mortality rate of $30-50 \%$ for every 20 -beatper-minute (bpm) increase in resting heart rate [13]. However, the importance of heart rate is often overlooked. Although experimental studies have suggested that lowering the heart rate may protect against cerebral ischemia by reducing oxidative stress and improving endothelial function [14], whether a lower initial in-hospital heart rate is associated with a better prognosis in patients with acute ischemic stroke (AIS) has yet to be elucidated. Therefore, the objective of this study was to evaluate the relationship between mean initial in-hospital heart rate and long-term 
mortality in a large population of AIS patients with an extended follow-up.

\section{Methods}

We conducted this retrospective cohort study using data from the Chang Gung Research Database [15], the largest multi-institutional electronic medical records collection in Taiwan. All patients who had an AIS (International Classification of Diseases, 9th Revision, Clinical Modification codes 433.01, 433.11, 433.21, 433.31, 433.81, 433.91, 434.01, 434.11, 434.91; International Classification of Diseases, 10th Revision, Clinical Modification [ICD-10] code I63) in the first two discharge diagnoses [16, 17] between January 2010 and September 2018, and were admitted to one of the seven branch hospitals of Chang Gung Healthcare System were accrued consecutively in this study. Key demographic and clinical characteristics were collected, including stroke severity as assessed using the claims-based stroke severity index (SSI). The SSI was then converted to the National Institutes of Health Stroke Scale score using the equation: estimated National Institutes of Health Stroke Scale (eNIH $\mathrm{SS})=1.1722 \times \mathrm{SSI}-0.7533$ [18]. Measurements of height, body weight, systolic blood pressure (SBP), diastolic blood pressure (DBP), heart rate, creatinine, alanine aminotransferase (ALT), glycated hemoglobin (HbA1c), and lipid profiles were obtained from the records of the enrolled patients. Heart rate, SBP, and DBP were measured with the patients recumbent after $5 \mathrm{~min}$ rest and were recorded using an automated oscillometric device (DINAMAP ProCare 100, GE Medical Systems, Milwaukee, WI, USA) or a bedside patient monitor (IntelliVue MP60, Philips Medical System, Boeblingen, Germany). If the pulse was irregular, heart rates were measured by palpating the radial pulse over a period of $60 \mathrm{~s}$. The mean heart rate was derived from recorded vital sign values in the first 3 days of hospitalization. Estimated glomerular filtration rate (eGFR) was determined using the Modification of Diet in Renal Disease equation as follows: eGFR $\left(\mathrm{mL} / \mathrm{min} / 1.73 \mathrm{~m}^{2}\right)=186 \times($ serum creatinine $)^{-1.154} \times(\text { age })^{-0.203} \times 0.742$ (if female) [19]. Chronic kidney disease (CKD) was classified into five stages: stage 1 (eGFR $\geq 90$ ), stage 2 (eGFR 60-89), stage 3 (eGFR 30-59), stage 4 (eGFR $15-29)$, and stage $5($ eGFR < 15) (all eGFR in $\mathrm{mL} / \mathrm{min} / 1.73 \mathrm{~m}^{2}$ ) [20].

The original cohort consisted of 41,241 patients aged $\geq 18$ years. The exclusion criteria were patients: (1) hospitalized for less than 3 days; (2) admitted to a rehabilitation unit; (3) admitted through outpatient clinics; (4) with recurrent stroke during the study period; and (5) with less than one record of heart rate per day in the first 3 days of hospitalization. In addition, those without catastrophic illness cards were also excluded (beneficiaries of the National
Health Insurance system in Taiwan would have been given a catastrophic illness card for 1 month because of their AIS; the National Health Insurance system in Taiwan covers more than $99.9 \%$ of the entire population) [21]. Finally, the data of 21,655 patients were used for the analysis (Fig. 1). The study was conducted in accordance with the Declaration of Helsinki and local ethical approval was obtained.

\section{Outcomes}

The primary outcome was all-cause mortality, and the secondary outcome was cardiovascular death. We linked to the National Registry of Deaths Database provided by the Ministry of Health and Welfare in Taiwan from January 1, 2010 to December 31, 2018. The database includes death certificates coded using ICD-10 codes. Cardiovascular diseases were classified as ICD-10 codes I00-I99.

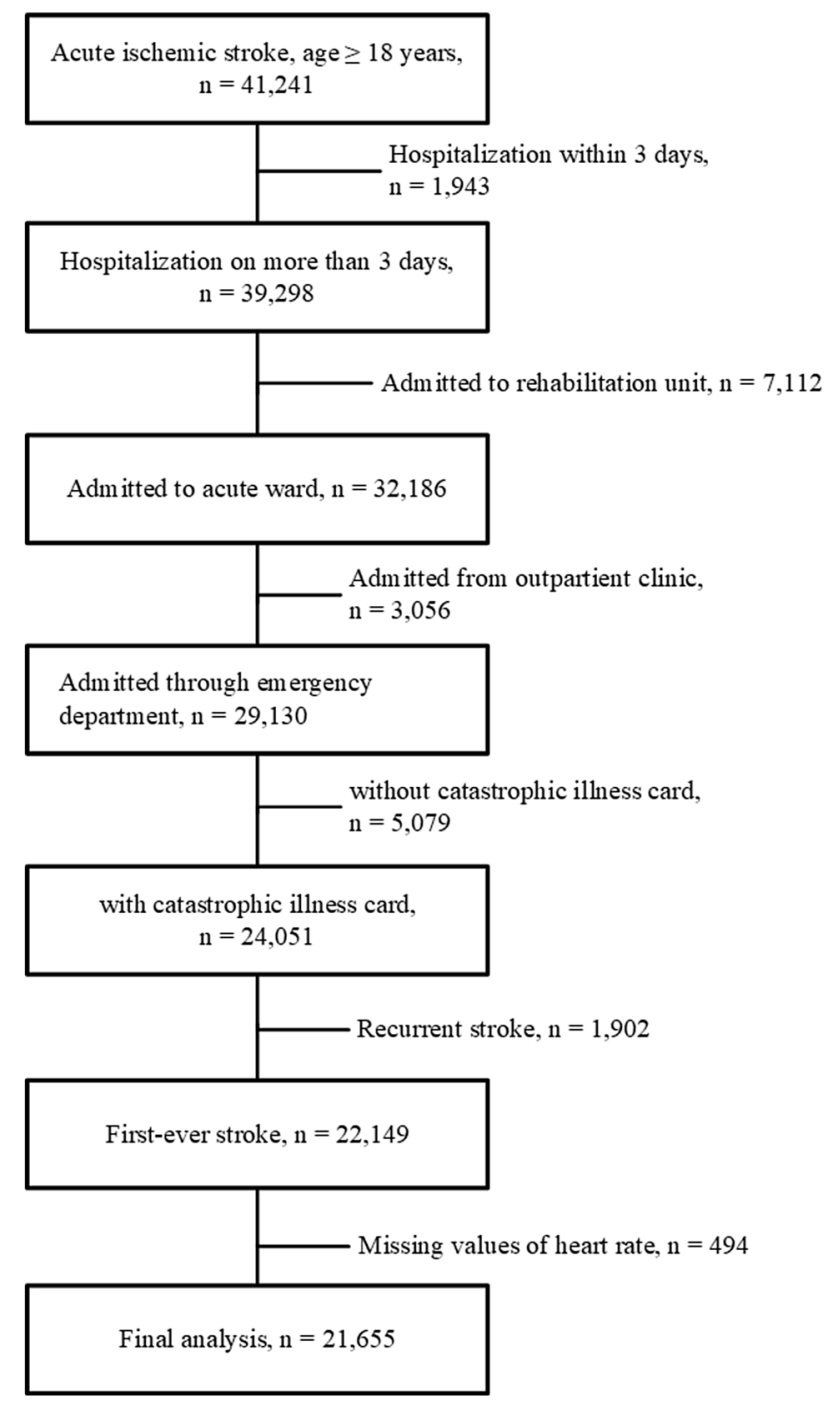

Fig. 1 Flowchart of patient selection 


\section{Statistical analysis}

Descriptive statistics are presented as number (percentage) for categorical data and mean (standard deviation) and median (interquartile range) for continuous data. The patients were classified into five subgroups according to mean heart rate (heart rate $<60,60-69,70-79,80-89$, and $\geq 90 \mathrm{bpm}$ ). Differences between the groups were tested using the Kruskal-Wallis rank test for continuous data and the Chi-square test for categorical data. In addition to crude hazard ratios (HRs), adjusted HRs and 95\% confidence intervals (CIs) were calculated with reference to the lowest risk group and estimated after adjusting for potential confounding factors in the Cox proportional hazard models. Model 1 included age, sex, and eNIHSS, and model 2 included age, sex, eNIHSS, history of hypertension (HTN), diabetes mellitus (DM), dyslipidemia, atrial fibrillation (AF), congestive heart failure (CHF), cancer before admission, smoking status, beta blocking agents, body mass index (BMI), total cholesterol, triglycerides (TGs), CKD stage, ALT, HbA1c, mean SBP, and mean DBP.

Data analysis was conducted without imputing missing data. Variables with missing data were classified into a missing data category to minimize the effect of the missing data in the analysis.

Interactions between mean heart rate and age, sex, eNIHSS, history of HTN, DM, dyslipidemia, AF, CHF, cancer before admission, smoking status, beta blocking agents, BMI, total cholesterol, TGs, CKD stage, ALT, HbA1c, mean SBP, and mean DBP at baseline were tested. Subgroup analyses were performed with heart rate as a continuous variable and when interactions were significant even after adjusting for the same variables as in the Cox proportional hazard model (model 2). HRs and 95\% CIs for each subgroup were calculated for every one standard deviation increment in heart rate. A Cox model with restricted cubic spline smoothing technique was used to explore the overall trend of risks through the range of mean heart rate values. All analyses were performed with SAS (version 9.4, Cary, NC, USA) and $\mathrm{R}$ (version 4.0).

\section{Results}

\section{Baseline characteristics}

A total of 21,655 adult patients with AIS were included in the analysis (mean age, $67.37 \pm 12.92$ years; $61.88 \%$ males). The mean SBP and DBP were $151.04 \pm 19.64$ and $84.81 \pm 11.17 \mathrm{mmHg}$, respectively, and the mean heart rate was $74.84 \pm 11.27 \mathrm{bpm}$. There were 436,376 measurements of heart rate in this study. The median number of measurement per patient was 13 (interquartile range 9-18). The demographic data and baseline characteristics of the overall patient cohort and for each 10-bpm-increment heart rate subgroup are given in Table 1. After a median follow-up of 3.2 years (interquartile range $1.4-5.6$ years), 6345 patients (29.3\%) met the primary outcome (all-cause mortality) and 2584 patients $(11.9 \%)$ met the secondary outcome (cardiovascular death). Compared to the patients with a higher mean heart rate, those with a lower mean heart rate were more likely to be male, current smokers, without using beta blocking agent, to not have HTN or DM, and to have dyslipidemia, lower eNIHSS score, lower baseline incidence of $\mathrm{AF}$ and $\mathrm{CHF}$, lower prevalence of cancer, and lower baseline eGFR level.

\section{Clinical outcomes according to mean heart rate}

Crude and adjusted HRs for mean heart rate are given in Fig. 2. Compared with the reference group (mean heart rate $<60 \mathrm{bpm}$ ), the adjusted HRs for the all-cause mortality in model 2 was 1.23 (95\% CI 1.08-1.41) for mean heart rate 60-69 bpm, 1.74 (95\% CI 1.53-1.97) for mean heart rate 70-79 bpm, 2.16 (95\% CI 1.89-2.46) for mean heart rate 80-89 bpm, and 2.83 (95\% CI 2.46-3.25) for mean heart rate $\geq 90 \mathrm{bpm}$.

Besides a high mean heart rate, age, male sex, eNIHSS, DM, CHF, history of cancer before admission, and CKD stages $2-5$ were all positively associated with the risk of all-cause mortality. Conversely, a history of dyslipidemia, higher BMI, total cholesterol, ALT, and mean DBP levels showed a protective effect (Table 2).

Compared with the reference group (mean heart rate $<60 \mathrm{bpm}$ ), the adjusted HRs for cardiovascular death in model 2 were 1.18 (95\% CI 0.95-1.46) for mean heart rate $60-69 \mathrm{bpm}, 1.57$ (95\% CI 1.28-1.93) for mean heart rate $70-79 \mathrm{bpm}, 1.98$ (95\% CI 1.60-2.45) for mean heart rate 80-89 bpm, and 2.36 (95\% CI 1.89-2.95) for mean heart rate $\geq 90 \mathrm{bpm}$ (Fig. 2). In addition to a higher mean heart rate, age, male sex, eNIHSS, AF, CHF, and CKD stages 2-5 were still associated with cardiovascular death. A history of dyslipidemia, higher BMI, total cholesterol, ALT, and mean DBP levels showed a protective effect (Table 2).

Even after multiple adjustments for potential confounding factors, no J-shaped curve was found for the occurrence of the primary and secondary outcomes. A higher mean heart rate was significantly and continuously associated with increased HRs of all-cause mortality and cardiovascular death (Fig. 3).

\section{Subgroup analysis}

Interaction analyses are presented in Supplementary Table 1. Significant effect modifications of age, sex, eNIHSS, HTN, DM, AF, CHF, history of cancer before 
Table 1 Demographic and baseline characteristics of the overall cohort stratified by mean heart rate

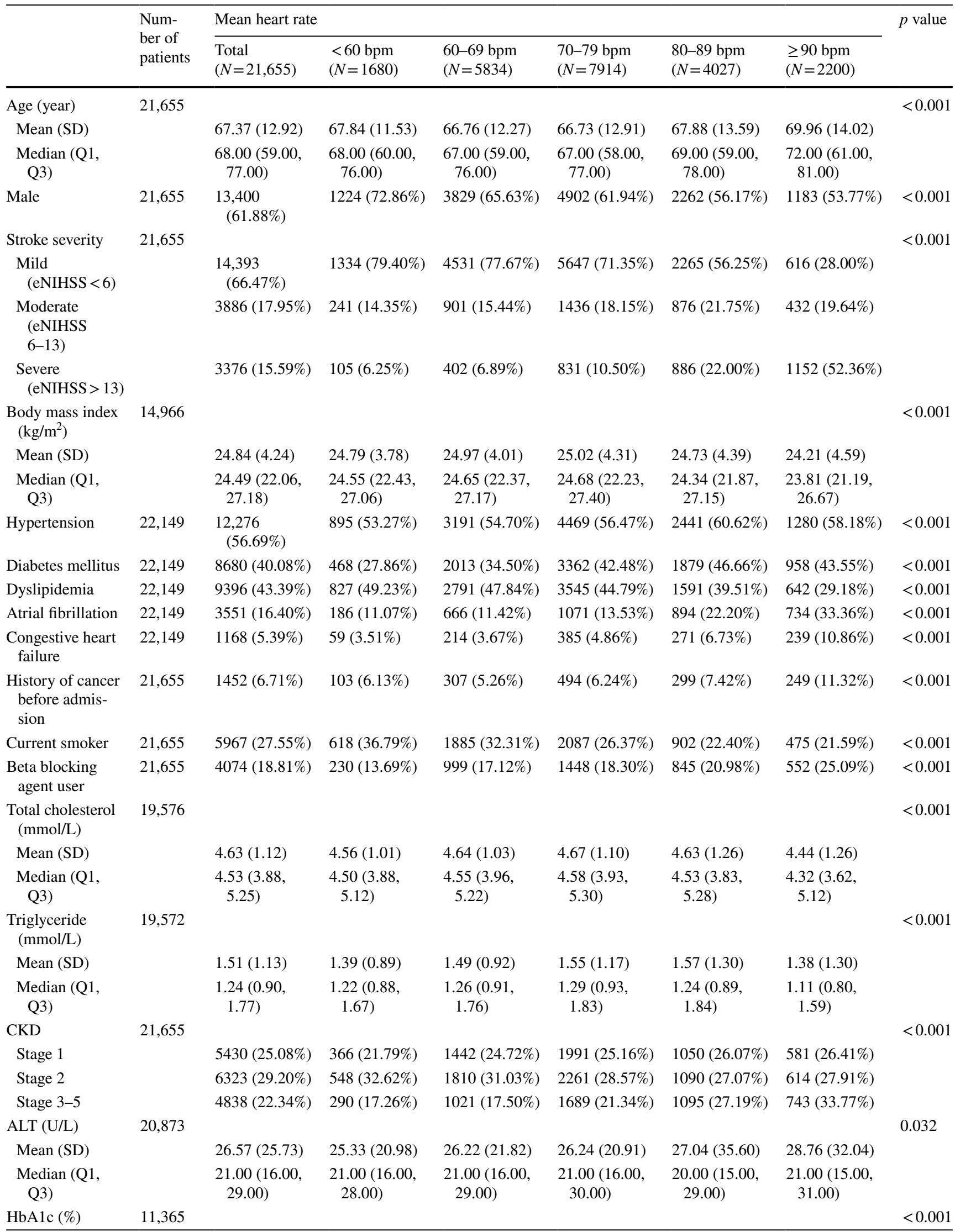


Table 1 (continued)

\begin{tabular}{|c|c|c|c|c|c|c|c|c|}
\hline & \multirow{2}{*}{$\begin{array}{l}\text { Num- } \\
\text { ber of } \\
\text { patients }\end{array}$} & \multicolumn{6}{|l|}{ Mean heart rate } & \multirow[t]{2}{*}{$p$ value } \\
\hline & & $\begin{array}{l}\text { Total } \\
(N=21,655)\end{array}$ & $\begin{array}{l}<60 \mathrm{bpm} \\
(N=1680)\end{array}$ & $\begin{array}{l}60-69 \mathrm{bpm} \\
(N=5834)\end{array}$ & $\begin{array}{l}70-79 \mathrm{bpm} \\
(N=7914)\end{array}$ & $\begin{array}{l}80-89 \text { bpm } \\
(N=4027)\end{array}$ & $\begin{array}{l}\geq 90 \mathrm{bpm} \\
(N=2200)\end{array}$ & \\
\hline Mean (SD) & & $6.89(1.89)$ & $6.37(1.28)$ & $6.68(1.71)$ & $6.93(1.89)$ & $7.17(2.10)$ & $7.15(2.16)$ & \\
\hline $\begin{array}{l}\text { Median (Q1, } \\
\text { Q3) }\end{array}$ & & $\begin{array}{l}6.10(5.70, \\
7.40)\end{array}$ & $\begin{array}{l}5.90(5.60, \\
6.50)\end{array}$ & $\begin{array}{l}6.00(5.70 \\
7.00)\end{array}$ & $\begin{array}{l}6.20(5.70, \\
7.60)\end{array}$ & $\begin{array}{l}6.30(5.70, \\
8.00)\end{array}$ & $\begin{array}{l}6.30(5.70 \\
7.90)\end{array}$ & \\
\hline $\begin{array}{r}\text { Mean SBP } \\
(\mathrm{mmHg})\end{array}$ & 21,622 & & & & & & & $<0.001$ \\
\hline Mean (SD) & & $151.04(19.64)$ & $153.40(20.27)$ & $151.95(19.52)$ & $150.73(19.13)$ & $151.58(20.01)$ & $146.91(19.98)$ & \\
\hline $\begin{array}{l}\text { Median (Q1, } \\
\text { Q3) }\end{array}$ & & $\begin{array}{l}150.11(137.20 \\
164.46)\end{array}$ & $\begin{array}{l}153.14(139.40 \\
167.60)\end{array}$ & $\begin{array}{l}151.28(138.14 \\
165.28)\end{array}$ & $\begin{array}{c}149.22(137.09, \\
163.67)\end{array}$ & $\begin{array}{l}151.11(137.87 \\
165.42)\end{array}$ & $\begin{array}{l}146.06(132.96 \\
160.95)\end{array}$ & \\
\hline $\begin{array}{c}\text { Mean DBP } \\
(\mathrm{mmHg})\end{array}$ & 21,609 & & & & & & & $<0.001$ \\
\hline Mean (SD) & & 84.81 (11.17) & $82.56(10.97)$ & 84.38 (10.94) & $85.21(10.69)$ & $86.02(11.67)$ & $84.01(12.28)$ & \\
\hline $\begin{array}{l}\text { Median (Q1, } \\
\text { Q3) }\end{array}$ & & $\begin{array}{l}84.27(77.22 \\
92.14)\end{array}$ & $\begin{array}{l}82.18(75.19 \\
89.45)\end{array}$ & $\begin{array}{l}83.85(76.86 \\
91.45)\end{array}$ & $\begin{array}{l}84.41(78.00 \\
92.00)\end{array}$ & $\begin{array}{l}85.53(78.00 \\
94.17)\end{array}$ & $\begin{array}{l}84.00(75.86 \\
92.50)\end{array}$ & \\
\hline
\end{tabular}

bpm beats per minute; $S D$ standard deviation; $Q$ quartile; $e N I H S S$ estimated National Institute of Health Stroke Scale; $B M I$ body mass index; $H T N$ hypertension; $D M$ diabetes mellitus; $A F$ atrial fibrillation; $C H F$ congestive heart failure; $C K D$ chronic kidney disease; $A L T$ alanine aminotransferase; $H b A l c$ glycated hemoglobin; $S B P$ systolic blood pressure; $D B P$ diastolic blood pressure

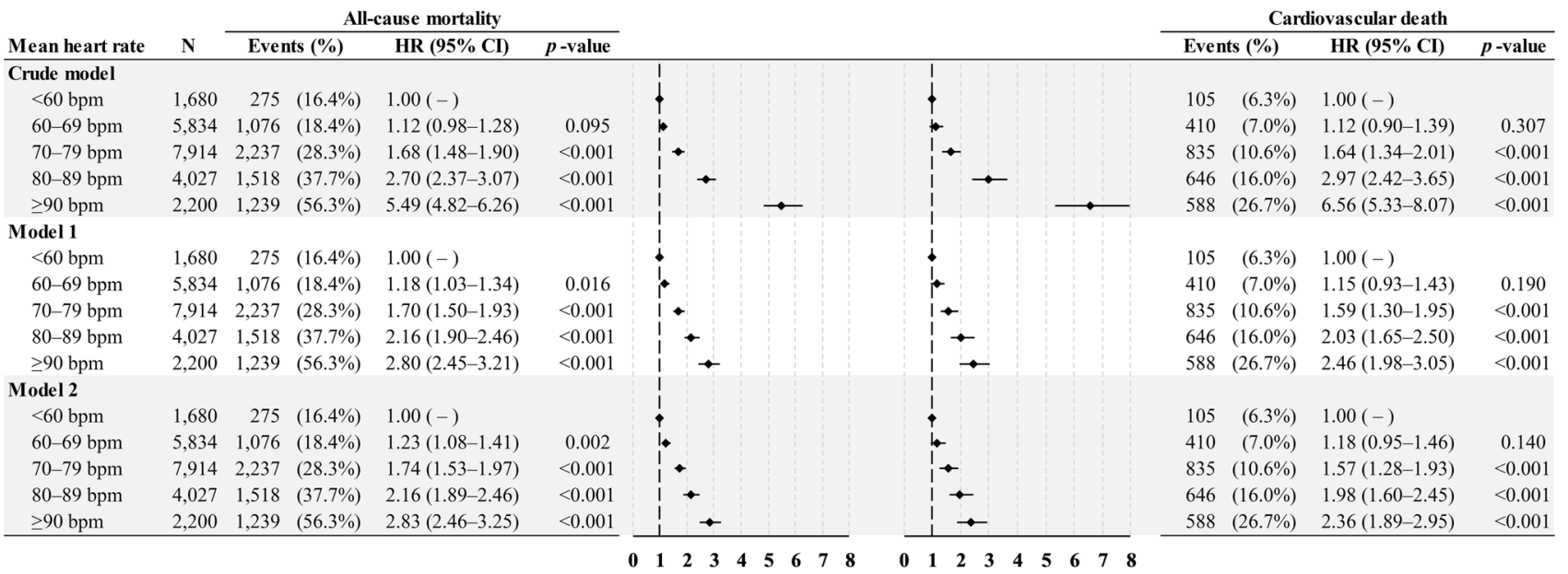

Fig. 2 Forest plots of crude and adjusted hazard ratios (95\% CIs) of the primary outcome (all-cause mortality) and secondary outcome (cardiovascular death) by mean initial in-hospital heart rate increments. The analyses were adjusted for age and estimated National Institutes of Health Stroke Scale score in model 1, and all of the variables in the fully adjusted model (model 2), including age, sex, estimated National Institutes of Health Stroke Scale score, history

admission, Beta blocking agent, total cholesterol, CKD stage, ALT, HbA1c, and mean SBP at baseline were detected on the relationship between mean heart rate and the primary outcome. An association between mean heart rate and long-term mortality was found in all analyzed subgroups (Fig. 4). of hypertension, diabetes mellitus, dyslipidemia, atrial fibrillation, congestive heart failure, cancer before admission, smoking status, beta blocking agent, body mass index, total cholesterol, triglycerides, chronic kidney disease stage, alanine aminotransferase, glycated hemoglobin, mean systolic blood pressure, and mean diastolic blood pressure. $N$ number; $H R$ hazard ratio; $C I$ confidence interval; $b p m$ beats per minute 
Table 2 Multivariable Cox regression models for all-cause mortality and cardiovascular death

\begin{tabular}{|c|c|c|c|c|c|c|}
\hline \multirow[t]{2}{*}{ Variables } & \multicolumn{3}{|c|}{ All-cause mortality } & \multicolumn{3}{|c|}{ Cardiovascular death } \\
\hline & HR & $95 \% \mathrm{CI}$ & $p$ value & $\mathrm{HR}$ & $95 \% \mathrm{CI}$ & $p$ value \\
\hline \multicolumn{7}{|l|}{ Mean heart rate (ref: $<60 \mathrm{bpm})$} \\
\hline 60-69 bpm & 1.23 & $1.08-1.41$ & 0.002 & 1.18 & $0.95-1.46$ & 0.140 \\
\hline 70-79 bpm & 1.74 & $1.53-1.97$ & $<0.001$ & 1.57 & $1.28-1.93$ & $<0.001$ \\
\hline $80-89$ bpm & 2.16 & $1.89-2.46$ & $<0.001$ & 1.98 & $1.60-2.45$ & $<0.001$ \\
\hline$\geq 90 \mathrm{bpm}$ & 2.83 & $2.46-3.25$ & $<0.001$ & 2.36 & $1.89-2.95$ & $<0.001$ \\
\hline Age & 1.041 & $1.039-1.044$ & $<0.001$ & 1.038 & $1.034-1.043$ & $<0.001$ \\
\hline Male (ref: female) & 1.38 & $1.30-1.46$ & $<0.001$ & 1.35 & $1.24-1.48$ & $<0.001$ \\
\hline eNIHSS & 1.085 & $1.080-1.090$ & $<0.001$ & 1.118 & $1.110-1.125$ & $<0.001$ \\
\hline HTN (ref: without HTN) & 0.99 & $0.94-1.05$ & 0.756 & 1.08 & $0.99-1.17$ & 0.074 \\
\hline DM (ref: without DM) & 1.17 & $1.10-1.24$ & $<0.001$ & 0.92 & $0.84-1.02$ & 0.105 \\
\hline Dyslipidemia (ref: without dyslipidemia) & 0.73 & $0.69-0.78$ & $<0.001$ & 0.84 & $0.76-0.92$ & $<0.001$ \\
\hline $\mathrm{AF}$ (ref: without $\mathrm{AF}$ ) & 0.99 & $0.93-1.06$ & 0.781 & 1.15 & $1.05-1.27$ & 0.003 \\
\hline CHF (ref: without CHF) & 1.33 & $1.22-1.45$ & $<0.001$ & 1.39 & $1.22-1.58$ & $<0.001$ \\
\hline Cancer (ref: without Cancer) & 2.13 & $1.97-2.30$ & $<0.001$ & 0.99 & $0.84-1.16$ & 0.869 \\
\hline Smoker (ref: non-smoker) & 0.98 & $0.92-1.05$ & 0.598 & 0.98 & $0.88-1.10$ & 0.769 \\
\hline Beta blocking agents user (ref: non-user) & 0.98 & $0.92-1.05$ & 0.598 & 1.07 & $0.98-1.18$ & 0.133 \\
\hline \multicolumn{7}{|l|}{ BMI (ref: $\geq 18.5,<24)$} \\
\hline$<18.5$ & 1.40 & $1.25-1.57$ & $<0.001$ & 1.39 & $1.17-1.65$ & $<0.001$ \\
\hline$\geq 24,<27$ & 0.78 & $0.73-0.85$ & $<0.001$ & 0.81 & $0.72-0.92$ & 0.001 \\
\hline$\geq 27,<30$ & 0.74 & $0.67-0.82$ & $<0.001$ & 0.87 & $0.74-1.01$ & 0.070 \\
\hline$\geq 30$ & 0.68 & $0.60-0.79$ & $<0.001$ & 0.82 & $0.67-1.01$ & 0.060 \\
\hline Missing & 1.07 & $1.00-1.13$ & 0.053 & 1.25 & $1.13-1.38$ & $<0.001$ \\
\hline \multicolumn{7}{|l|}{ Total cholesterol (ref: $\leq \mathrm{Q} 1)$} \\
\hline$>\mathrm{Q} 1, \leq$ median & 0.87 & $0.81-0.93$ & $<0.001$ & 0.88 & $0.79-0.98$ & 0.024 \\
\hline$>$ median, $\leq \mathrm{Q} 3$ & 0.86 & $0.79-0.92$ & $<0.001$ & 0.82 & $0.72-0.92$ & 0.001 \\
\hline$>\mathrm{Q} 3$ & 0.88 & $0.81-0.95$ & 0.002 & 0.86 & $0.75-0.98$ & 0.023 \\
\hline Missing & 1.08 & $0.64-1.82$ & 0.774 & 1.22 & $0.58-2.59$ & 0.601 \\
\hline \multicolumn{7}{|l|}{ Triglyceride (ref: $\leq \mathrm{Q} 1)$} \\
\hline$>\mathrm{Q} 1, \leq$ median & 0.96 & $0.89-1.03$ & 0.251 & 0.97 & $0.87-1.08$ & 0.556 \\
\hline$>$ Median, $\leq \mathrm{Q} 3$ & 0.96 & $0.88-1.03$ & 0.250 & 0.97 & $0.86-1.09$ & 0.567 \\
\hline$>\mathrm{Q} 3$ & 0.98 & $0.90-1.07$ & 0.640 & 0.95 & $0.82-1.09$ & 0.433 \\
\hline Unknown & 0.75 & $0.45-1.27$ & 0.286 & 0.66 & $0.31-1.40$ & 0.275 \\
\hline \multicolumn{7}{|l|}{ CKD (ref: stage 1) } \\
\hline Stage 2 & 1.13 & $1.06-1.22$ & 0.001 & 1.25 & $1.11-1.39$ & $<0.001$ \\
\hline Stage $3-5$ & 1.79 & $1.66-1.92$ & $<0.001$ & 1.79 & $1.61-2.01$ & $<0.001$ \\
\hline Unknown & 0.87 & $0.80-0.95$ & 0.002 & 0.78 & $0.68-0.91$ & 0.001 \\
\hline \multicolumn{7}{|l|}{ ALT (ref: $\leq \mathrm{Q} 1)$} \\
\hline$>\mathrm{Q} 1, \leq$ median & 0.79 & $0.74-0.84$ & $<0.001$ & 0.77 & $0.69-0.86$ & $<0.001$ \\
\hline$>$ Median, $\leq \mathrm{Q} 3$ & 0.77 & $0.71-0.83$ & $<0.001$ & 0.76 & $0.68-0.85$ & $<0.001$ \\
\hline$>\mathrm{Q} 3$ & 0.88 & $0.82-0.94$ & $<0.001$ & 0.83 & $0.74-0.93$ & 0.001 \\
\hline Unknown & 0.86 & $0.74-0.99$ & 0.037 & 0.91 & $0.72-1.14$ & 0.416 \\
\hline \multicolumn{7}{|l|}{ HbA1c (ref: $\leq \mathrm{Q} 1)$} \\
\hline$>\mathrm{Q} 1, \leq$ median & 0.95 & $0.86-1.04$ & 0.262 & 1.04 & $0.89-1.21$ & 0.609 \\
\hline$>$ Median, $\leq$ Q3 & 1.03 & $0.94-1.14$ & 0.543 & 1.20 & $1.03-1.40$ & 0.017 \\
\hline$>\mathrm{Q} 3$ & 1.11 & $1.00-1.24$ & 0.054 & 1.18 & $0.98-1.41$ & 0.076 \\
\hline Unknown & 1.13 & $1.05-1.22$ & 0.001 & 1.25 & $1.11-1.40$ & $<0.001$ \\
\hline \multicolumn{7}{|l|}{ Mean SBP (ref: < $130 \mathrm{mmHg}$ ) } \\
\hline$\geq 130,<140 \mathrm{mmHg}$ & 0.87 & $0.80-0.95$ & 0.002 & 0.85 & $0.74-0.97$ & 0.018 \\
\hline$\geq 140,<150 \mathrm{mmHg}$ & 0.87 & $0.80-0.95$ & 0.003 & 0.84 & $0.73-0.96$ & 0.013 \\
\hline
\end{tabular}


Table 2 (continued)

\begin{tabular}{|c|c|c|c|c|c|c|}
\hline \multirow[t]{2}{*}{ Variables } & \multicolumn{3}{|c|}{ All-cause mortality } & \multicolumn{3}{|c|}{ Cardiovascular death } \\
\hline & HR & $95 \% \mathrm{CI}$ & $p$ value & HR & $95 \% \mathrm{CI}$ & $p$ value \\
\hline$\geq 150,<160 \mathrm{mmHg}$ & 0.93 & $0.85-1.03$ & 0.151 & 0.86 & $0.74-1.00$ & 0.045 \\
\hline$\geq 160 \mathrm{mmHg}$ & 1.09 & $0.99-1.20$ & 0.091 & 1.01 & $0.87-1.18$ & 0.882 \\
\hline Unknown & 1.08 & $0.23-5.13$ & 0.921 & 0.89 & $0.14-5.57$ & 0.899 \\
\hline \multicolumn{7}{|c|}{ Mean DBP (ref: $<70 \mathrm{mmHg}$ ) } \\
\hline$\geq 70,<80 \mathrm{mmHg}$ & 0.83 & $0.77-0.91$ & $<0.001$ & 0.86 & $0.75-0.97$ & 0.018 \\
\hline$\geq 80,<90 \mathrm{mmHg}$ & 0.69 & $0.62-0.75$ & $<0.001$ & 0.77 & $0.67-0.89$ & $<0.001$ \\
\hline$\geq 90,<100 \mathrm{mmHg}$ & 0.67 & $0.60-0.75$ & $<0.001$ & 0.79 & $0.66-0.94$ & 0.008 \\
\hline$\geq 100 \mathrm{mmHg}$ & 0.61 & $0.52-0.71$ & $<0.001$ & 0.78 & $0.62-0.99$ & 0.044 \\
\hline Unknown & 0.39 & $0.09-1.71$ & 0.212 & 0.59 & $0.11-3.13$ & 0.531 \\
\hline
\end{tabular}

$H R$ hazard ratio; $C I$ confidence interval; $r e f$ reference; $b p m$ beats per minute; $e N I H S S$ estimated National Institute of Health Stroke Scale; $H T N$ hypertension; $D M$ diabetes mellitus; $A F$ atrial fibrillation; $C H F$ congestive heart failure; $B M I$ body mass index; $Q$ quartile; $C K D$ chronic kidney disease; $A L T$ alanine aminotransferase; $H b A l c$ glycated hemoglobin; $S B P$ systolic blood pressure; $D B P$ diastolic blood pressure

\section{(A) Risk for all-cause mortality}

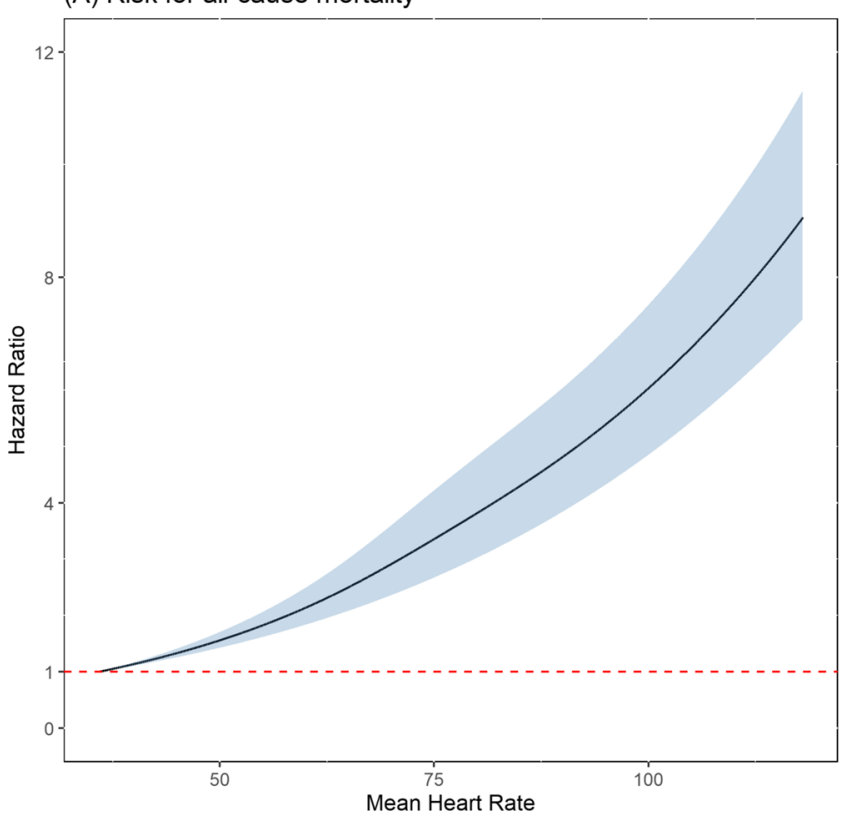

Fig. 3 Restricted cubic splines are represented for the associations between mean initial in-hospital heart rate levels and study outcomes (all-cause mortality and cardiovascular death). The analyses were adjusted for all of the variables in the fully adjusted model, including age, sex, estimated National Institutes of Health Stroke Scale score, history of hypertension, diabetes mellitus, dyslipidemia, atrial fibril-

The size of the study cohort allowed us to adjust for two of the strongest predictors of mortality in the multivariable model: age and stroke severity. In the subgroup analysis according to different age and stroke severity groups, the association between initial in-hospital heart rate and long-term mortality was consistent (Fig. 4). The impact of increasing heart rate on all-cause mortality seemed to be

\section{(B) Risk for cardiovascular death}

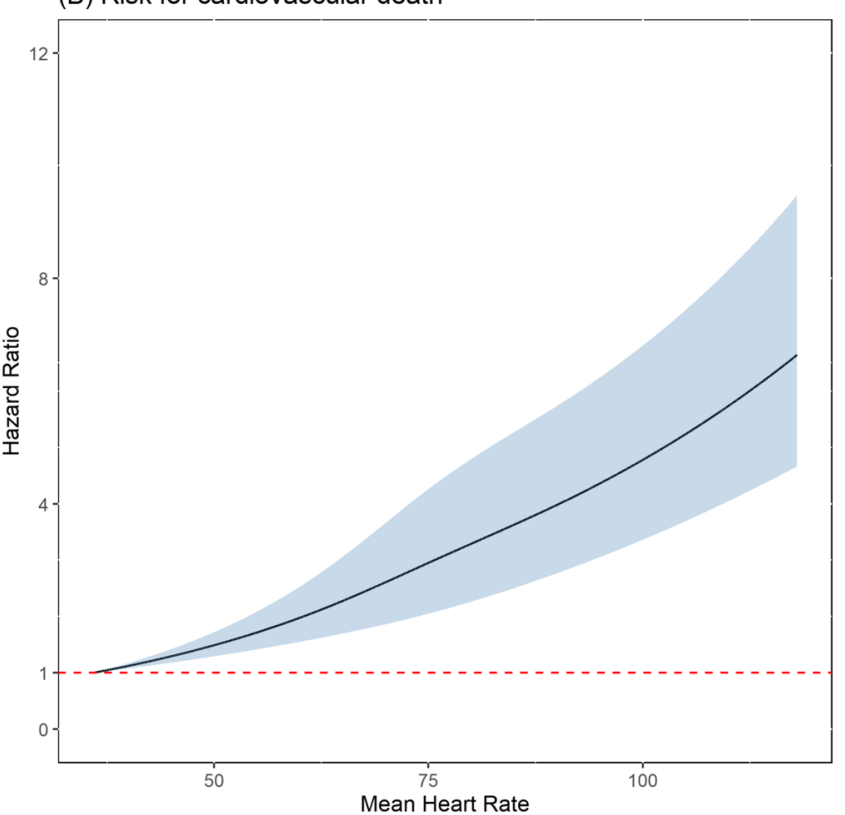

lation, congestive heart failure, cancer before admission, smoking status, beta blocking agent, body mass index, total cholesterol, triglycerides, chronic kidney disease stage, alanine aminotransferase, glycated hemoglobin, mean systolic blood pressure, and mean diastolic blood pressure

more pronounced in the patients younger than 75 years and in those with mild-to-moderate stroke (Fig. 4).

Epidemiological studies have consistently shown that resting heart rate is a predictor of all-cause and cardiovascular mortality in the general population and in patients with cardiovascular disease [22-24]. However, the previous studies have reported inconsistent results about the relationship 
Fig. 4 Subgroup analyses of allcause mortality and cardiovascular death per standard deviation ( 10.8 beats per minute) of heart rate increment. $e$ NIHSS estimated National Institutes of Health Stroke Scale; $C K D$ chronic kidney disease; HbA1c, glycated hemoglobin; $S B P$ systolic blood pressure; $H R$ hazard ratio; $C I$ confidence interval; $S D$ standard deviation

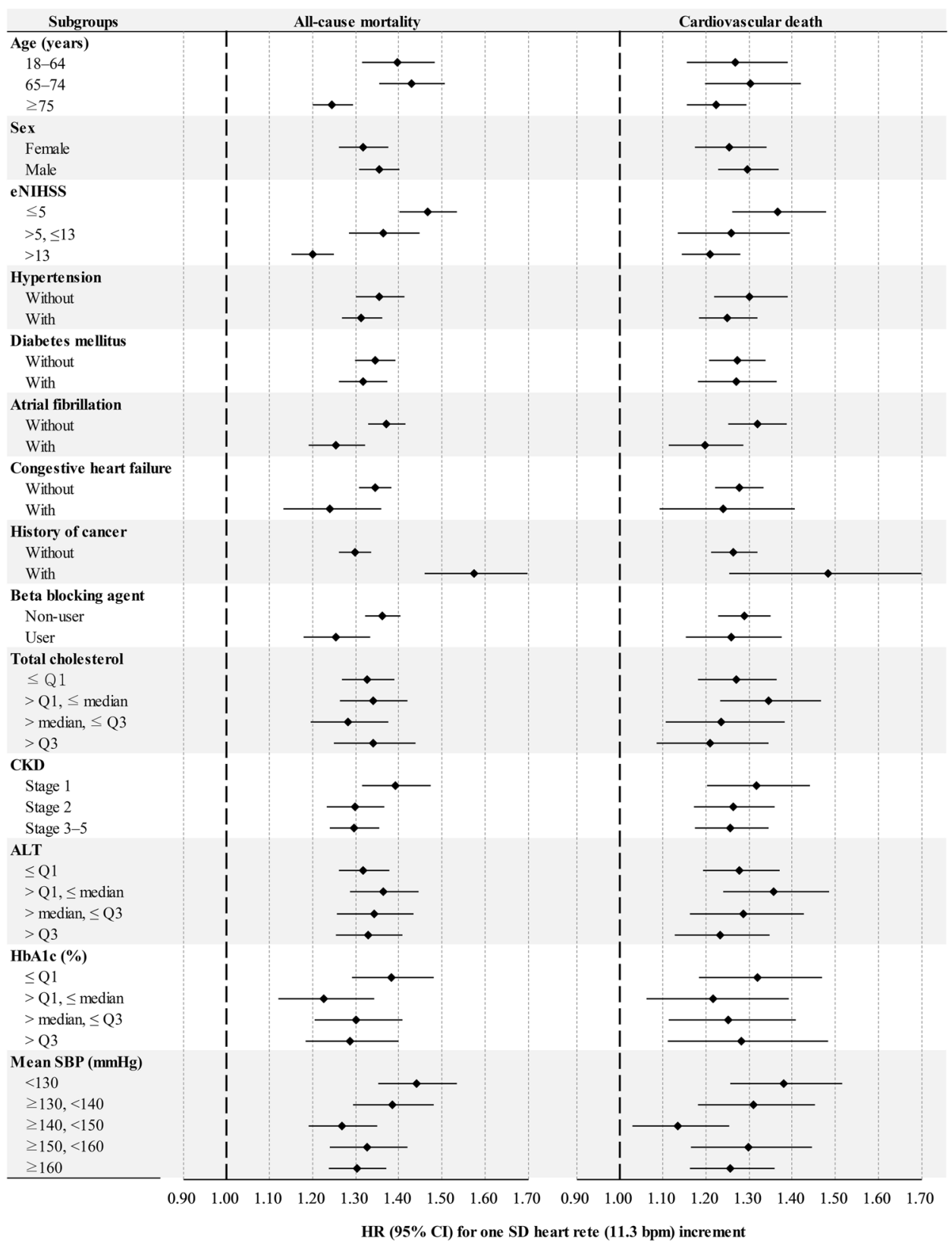

between heart rate and the clinical outcomes of patients with AIS. The Prevention Regimen for Effectively Avoiding Second Strokes study reported that heart rate was a risk factor for mortality in stroke patients, and, importantly, that a low heart rate was associated with better functional outcomes and lower rates of cognitive impairment after an AIS [25]. In addition, the Gutenberg Health Study reported that both a higher and lower heart rate were associated with a higher risk of mortality [26]. However, Ritter et al. reported that significant tachycardia or bradycardia in AIS did not independently predict the clinical course or outcomes [27]. A higher resting heart rate at admission has also been reported to be independently associated with in-hospital mortality in
AIS patients without AF [28]. In addition, Lee et al. reported that in patients with AF hospitalized for AIS, the mean heart rate during the acute period was not associated with stroke recurrence, but was associated with mortality (nonlinear, J-shaped association) [29]. In the present study, mean initial in-hospital heart rate was associated with long-term all-cause and cardiovascular mortality in the overall cohort (Fig. 2), and in the patients with and without AF (Fig. 4). However, the effect of heart rate on long-term mortality seemed to be more pronounced in the patients without AF than in those with AF (Fig. 4). We also found that the longterm survival progressively declined as the level of mean initial in-hospital heart rate increased; however, there was 
no clear evidence of a J-curve relationship between the mean initial in-hospital heart rate and long-term mortality (Fig. 3).

In the multivariable Cox regression analysis, history of dyslipidemia, higher total cholesterol levels, and higher BMI are associated with improved long-term survival after AIS (Table 2). Although dyslipidemia and high BMI are wellknown risk factors for cardiovascular disease, this has not been the case for post-stroke mortality. From several large cohorts, blood lipid levels and BMI have generally been inversely associated with post-stroke mortality [30-32]. There may be unknown protective factors associated with dyslipidemia and high BMI.

Although heart rate is traditionally considered to be a risk factor for cardiovascular disease [33], we found that high initial in-hospital heart rate was a risk factor for both cardiovascular death and all-cause mortality after AIS in the current study. In the long-term follow-up of this study, cardiovascular death and cancer were the leading and secondary causes of death ( $40.7 \%$ and $17.1 \%$ of total mortality), respectively. Benetos et al. reported that heart rate was a predictive factor for non-cardiovascular mortality in both men and women in a French population [34]. Another prospective population study also reported that an increased mortality risk associated with a high heart rate was related mainly to diseases of non-cardiovascular or non-malignant origin [35]. However, many studies have demonstrated an association between an elevated heart rate and increased risks of cancer recurrence and mortality [36-38]. For example, a previous meta-analysis found that a higher resting heart rate was associated with increased risks of coronary heart disease, sudden cardiac death, heart failure, AF, stroke, cardiovascular disease, total cancer, and all-cause mortality [39].

Heart rate has been associated with plaque vulnerability, sympathetic hyperactivity, and atherosclerosis [40-42], and therefore, the role of arterial stress related to heart rate in the underlying mechanisms of the progression and clinical manifestations of cardiovascular diseases has gained increasing attention. In this study, the patients with a higher resting heart rate had more cardiovascular risk factors than those in the lowest group (Table 1). Some investigators have also indicated that many cardiovascular risk factors are also related to sympathetic hyperactivity [43-45]. Reduction of heart rate has been shown to delay the progression of coronary atherosclerosis in monkeys [46, 47], and reduce the rate of increase in carotid intima-media thickness in asymptomatic patients [48]. In a model of dyslipidemic mice, chronic heart rate reduction via ivabradine maintained cerebral endothelial function and prevented cerebral artery remodeling [49]. However, whether beta-blockers, calcium-channel blockers, or I(f) channel inhibitor are associated with survival benefit in patients with coronary artery disease is still inconclusive [50-52]. In addition to the above agents, cholinesterase inhibitors can also slow the heart rate via increasing cholinergic effect and show some potential in improving the lifespan [53-55]; however, further studies are needed to investigate whether they can improve survival after AIS. We hope that using appropriate medications to reduce heart rate may play a role in improving the long-term survival after AIS in the future.

\section{Limitations of this study}

The current study has a large sample size and addresses the prognostic implications of initial in-hospital heart rate. However, as with all observational studies, this study has several limitations. First, to collect the vital signs for the first 3 days of hospitalization, patients who were hospitalized for less than 3 days were excluded from the study, and so some patients with mild stroke may have been missed. Second, the link between mean initial in-hospital heart rate and death may not necessarily imply a cause-effect relationship. Third, this study was performed with a population of patients with AIS; therefore, our results may not be applicable to patients with other cardiovascular diseases.

\section{Conclusion}

Heart rate is a simple measurement with important prognostic implications in patients with AIS, and it should no longer be neglected in risk flowcharts.

Supplementary Information The online version contains supplementary material available at https://doi.org/10.1007/s00392-021-01953-5.

Acknowledgements The authors would like to thank Health Information and Epidemiology Laboratory (CLRPG6L0041) for the comments and assistance in data analysis.

Author contributions J.L. and T.L. designed the research, collected data, analyzed and interpreted data, and wrote the manuscript; Y.K analyzed and interpreted data and contributed to subsequent manuscript discussion; C.L. performed statistical analysis and contributed to subsequent manuscript discussion; Y.H and M.L. performed the research and contributed to subsequent manuscript discussion.

Funding This work was supported by grants from Chang Gung Memorial Hospital (CGRPG6L0041). The sponsors played no role in the study design, data collection and analysis, or decision to submit the article for publication.

Availability of data and materials The data supporting the findings of the article are available in the Chang Gung Research Databank at Chang Gung Memorial Hospital, Chiayi Branch. These data can be available after obtaining approval from our local IRB.

Code availability Not applicable. 


\section{Declarations}

Conflict of interest The authors declare that they do not have any conflicts of interest.

Ethics approval The study was approved by the local Institutional Review Board of Chang Gung Memorial Hospital, Chiayi Branch, Taiwan (202001990B0C501). All methods were carried out in accordance with relevant guidelines and regulations.

Consent to participate Before being released for analysis, the clinical data are anonymized and de-identified to ensure confidentiality; thus, the need for informed consent was waived.

Consent for publication All authors read and consented to the final manuscript version for publication.

Open Access This article is licensed under a Creative Commons Attribution 4.0 International License, which permits use, sharing, adaptation, distribution and reproduction in any medium or format, as long as you give appropriate credit to the original author(s) and the source, provide a link to the Creative Commons licence, and indicate if changes were made. The images or other third party material in this article are included in the article's Creative Commons licence, unless indicated otherwise in a credit line to the material. If material is not included in the article's Creative Commons licence and your intended use is not permitted by statutory regulation or exceeds the permitted use, you will need to obtain permission directly from the copyright holder. To view a copy of this licence, visit http://creativecommons.org/licenses/by/4.0/.

\section{References}

1. Bronnum-Hansen H, Davidsen M, Thorvaldsen P, Danish MSG (2001) Long-term survival and causes of death after stroke. Stroke 32:2131-2136

2. Singh RJ, Chen S, Ganesh A, Hill MD (2018) Long-term neurological, vascular, and mortality outcomes after stroke. Int J Stroke 13:787-796

3. Chen Y, Wright N, Guo Y, Turnbull I, Kartsonaki C, Yang L, Bian Z, Pei P, Pan D, Zhang Y et al (2020) Mortality and recurrent vascular events after first incident stroke: a 9-year communitybased study of 0.5 million Chinese adults. Lancet Glob Health 8:e580-e590

4. Levine HJ (1997) Rest heart rate and life expectancy. J Am Coll Cardiol 30:1104-1106

5. Kannel WB, Kannel C, Paffenbarger RS Jr, Cupples LA (1987) Heart rate and cardiovascular mortality: the Framingham Study. Am Heart J 113:1489-1494

6. Gillman MW, Kannel WB, Belanger A, D'Agostino RB (1993) Influence of heart rate on mortality among persons with hypertension: the Framingham Study. Am Heart J 125:1148-1154

7. Bohm M, Swedberg K, Komajda M, Borer JS, Ford I, DubostBrama A, Lerebours G, Tavazzi L, Investigators S (2010) Heart rate as a risk factor in chronic heart failure (SHIFT): the association between heart rate and outcomes in a randomised placebocontrolled trial. Lancet 376:886-894

8. Zhao MX, Zhao Q, Zheng M, Liu T, Li Y, Wang M, Yao S, Wang $\mathrm{C}$, Chen YM, Xue H et al (2020) Effect of resting heart rate on the risk of all-cause death in Chinese patients with hypertension: analysis of the Kailuan follow-up study. BMJ Open 10:e032699
9. Saxena A, Minton D, Lee DC, Sui X, Fayad R, Lavie CJ, Blair SN (2013) Protective role of resting heart rate on all-cause and cardiovascular disease mortality. Mayo Clin Proc 88:1420-1426

10. Li K, Yao C, Yang X, Dong L (2017) Effect of resting heart rate on all-cause mortality and cardiovascular events according to age. J Am Geriatr Soc 65:989-994

11. Diaz A, Bourassa MG, Guertin MC, Tardif JC (2005) Long-term prognostic value of resting heart rate in patients with suspected or proven coronary artery disease. Eur Heart J 26:967-974

12. Kristal-Boneh E, Silber H, Harari G, Froom P (2000) The association of resting heart rate with cardiovascular, cancer and all-cause mortality. Eight year follow-up of 3527 male Israeli employees (the CORDIS Study). Eur Heart J 21:116-124

13. Aboyans V, Criqui MH (2006) Can we improve cardiovascular risk prediction beyond risk equations in the physician's office? J Clin Epidemiol 59:547-558

14. Custodis F, Gertz K, Balkaya M, Prinz V, Mathar I, Stamm C, Kronenberg G, Kazakov A, Freichel M, Bohm M et al (2011) Heart rate contributes to the vascular effects of chronic mental stress: effects on endothelial function and ischemic brain injury in mice. Stroke 42:1742-1749

15. Tsai MS, Lin MH, Lee CP, Yang YH, Chen WC, Chang GH, Tsai YT, Chen PC, Tsai YH (2017) Chang Gung Research Database: a multi-institutional database consisting of original medical records. Biomed J 40:263-269

16. Sacco RL, Kasner SE, Broderick JP, Caplan LR, Connors JJ, Culebras A, Elkind MS, George MG, Hamdan AD, Higashida RT et al (2013) An updated definition of stroke for the 21st century: a statement for healthcare professionals from the American Heart Association/American Stroke Association. Stroke 44:2064-2089

17. Hsieh MT, Hsieh CY, Tsai TT, Wang YC, Sung SF (2020) Performance of ICD-10-CM diagnosis codes for identifying acute ischemic stroke in a national health insurance claims database. Clin Epidemiol 12:1007-1013

18. Sung SF, Hsieh CY, Lin HJ, Chen YW, Chen CH, Kao Yang YH, Hu YH (2016) Validity of a stroke severity index for administrative claims data research: a retrospective cohort study. BMC Health Serv Res 16:509

19. Levey AS, Bosch JP, Lewis JB, Greene T, Rogers N, Roth D (1999) A more accurate method to estimate glomerular filtration rate from serum creatinine: a new prediction equation. Modification of diet in renal disease study group. Ann Intern Med 130:461-470

20. Levey AS, Eckardt KU, Tsukamoto Y, Levin A, Coresh J, Rossert J, De Zeeuw D, Hostetter TH, Lameire N, Eknoyan G (2005) Definition and classification of chronic kidney disease: a position statement from kidney disease: improving global outcomes (KDIGO). Kidney Int 67:2089-2100

21. Cheng TM (2015) Reflections on the 20th anniversary of Taiwan's single-payer national health insurance system. Health Aff (Millwood) 34:502-510

22. Fox K, Borer JS, Camm AJ, Danchin N, Ferrari R, Lopez Sendon JL, Steg PG, Tardif JC, Tavazzi L, Tendera M et al (2007) Resting heart rate in cardiovascular disease. J Am Coll Cardiol 50:823-830

23. Palatini P (2007) Heart rate as an independent risk factor for cardiovascular disease: current evidence and basic mechanisms. Drugs 67(Suppl 2):3-13

24. Seccareccia F, Pannozzo F, Dima F, Minoprio A, Menditto A, Lo Noce C, Giampaoli S, Superiore MCAI, di Sanita P (2001) Heart rate as a predictor of mortality: the MATISS project. Am J Public Health 91:1258-1263

25. Bohm M, Cotton D, Foster L, Custodis F, Laufs U, Sacco R, Bath PM, Yusuf S, Diener HC (2012) Impact of resting heart rate on 
mortality, disability and cognitive decline in patients after ischaemic stroke. Eur Heart J 33:2804-2812

26. Munzel T, Hahad O, Gori T, Hollmann S, Arnold N, Prochaska JH, Schulz A, Beutel M, Pfeiffer N, Schmidtmann I et al (2019) Heart rate, mortality, and the relation with clinical and subclinical cardiovascular diseases: results from the Gutenberg Health Study. Clin Res Cardiol 108:1313-1323

27. Ritter MA, Rohde A, Heuschmann PU, Dziewas R, Stypmann J, Nabavi DG, Ringelstein BE (2011) Heart rate monitoring on the stroke unit. What does heart beat tell about prognosis? An observational study. BMC Neurol 11:47.

28. Han Q, Zhang C, You S, Zheng D, Zhong C, Dong H, Wang X, Pei S, Cao Y, Liu CF (2020) Resting heart rate and in-hospital mortality in acute ischemic stroke patients with and without atrial fibrillation. Circ J 84:656-661

29. Lee KJ, Kim BJ, Han MK, Kim JT, Choi KH, Shin DI, Yeo MJ, Cha JK, Kim DH, Nah HW et al (2020) Effect of heart rate on stroke recurrence and mortality in acute ischemic stroke with atrial fibrillation. Stroke 51:162-169

30. Yeramaneni S, Kleindorfer DO, Sucharew H, Alwell K, Moomaw CJ, Flaherty ML, Woo D, Adeoye O, Ferioli S, de Los Rios La Rosa F et al (2017) Hyperlipidemia is associated with lower risk of poststroke mortality independent of statin use: a populationbased study. Int J Stroke 12:152-160

31. Olsen TS, Dehlendorff C, Petersen HG, Andersen KK (2008) Body mass index and poststroke mortality. Neuroepidemiology 30:93-100

32. Aparicio HJ, Himali JJ, Beiser AS, Davis-Plourde KL, Vasan RS, Kase CS, Wolf PA, Seshadri S (2017) Overweight, obesity, and survival after stroke in the Framingham Heart Study. J Am Heart Assoc 6:e004721

33. Perret-Guillaume C, Joly L, Benetos A (2009) Heart rate as a risk factor for cardiovascular disease. Prog Cardiovasc Dis 52:6-10

34. Benetos A, Rudnichi A, Thomas F, Safar M, Guize L (1999) Influence of heart rate on mortality in a French population: role of age, gender, and blood pressure. Hypertension 33:44-52

35. Reunanen A, Karjalainen J, Ristola P, Heliovaara M, Knekt P, Aromaa A (2000) Heart rate and mortality. J Intern Med 247:231-239

36. Lee DH, Park S, Lim SM, Lee MK, Giovannucci EL, Kim JH, Kim SI, Jeon JY (2016) Resting heart rate as a prognostic factor for mortality in patients with breast cancer. Breast Cancer Res Treat 159:375-384

37. Park J, Kim JH, Park Y, Park SJ, Cheon JH, Kim WH, Park JS, Jeon JY, Kim TI (2018) Resting heart rate is an independent predictor of advanced colorectal adenoma recurrence. PLoS ONE 13:e0193753

38. Anker MS, Ebner N, Hildebrandt B, Springer J, Sinn M, Riess H, Anker SD, Landmesser U, Haverkamp W, von Haehling S (2016) Resting heart rate is an independent predictor of death in patients with colorectal, pancreatic, and non-small cell lung cancer: results of a prospective cardiovascular long-term study. Eur J Heart Fail 18:1524-1534

39. Aune D, Sen A, O'Hartaigh B, Janszky I, Romundstad PR, Tonstad S, Vatten LJ (2017) Resting heart rate and the risk of cardiovascular disease, total cancer, and all-cause mortality-a systematic review and dose-response meta-analysis of prospective studies. Nutr Metab Cardiovasc Dis 27:504-517

40. Dominguez-Rodriguez A, Blanco-Palacios G, Abreu-Gonzalez P (2011) Increased heart rate and atherosclerosis: potential implications of ivabradine therapy. World J Cardiol 3:101-104
41. Custodis F, Schirmer SH, Baumhakel M, Heusch G, Bohm M, Laufs U (2010) Vascular pathophysiology in response to increased heart rate. J Am Coll Cardiol 56:1973-1983

42. Palatini P, Julius S (1997) Association of tachycardia with morbidity and mortality: pathophysiological considerations. J Hum Hypertens 11(Suppl 1):S19-27

43. Festa A, D'Agostino R Jr, Hales CN, Mykkanen L, Haffner SM (2000) Heart rate in relation to insulin sensitivity and insulin secretion in nondiabetic subjects. Diabetes Care 23:624-628

44. Grynberg A, Ziegler D, Rupp H (1996) Sympathoadrenergic overactivity and lipid metabolism. Cardiovasc Drugs Ther 10(Suppl 1):223-230

45. Wang A, Liu X, Guo X, Dong Y, Wu Y, Huang Z, Xing A, Luo Y, Jonas JB, Wu S (2014) Resting heart rate and risk of hypertension: results of the Kailuan cohort study. J Hypertens 32:1600-1605; discussion 1605

46. Beere PA, Glagov S, Zarins CK (1984) Retarding effect of lowered heart rate on coronary atherosclerosis. Science 226:180-182

47. Kaplan JR, Manuck SB, Adams MR, Weingand KW, Clarkson TB (1987) Inhibition of coronary atherosclerosis by propranolol in behaviorally predisposed monkeys fed an atherogenic diet. Circulation 76:1364-1372

48. Hedblad B, Wikstrand J, Janzon L, Wedel H, Berglund G (2001) Low-dose metoprolol CR/XL and fluvastatin slow progression of carotid intima-media thickness: main results from the beta-blocker cholesterol-lowering asymptomatic plaque study (BCAPS). Circulation 103:1721-1726

49. Bolduc V, Drouin A, Gillis MA, Duquette N, Thorin-Trescases N, Frayne-Robillard I, Des Rosiers C, Tardif JC, Thorin E (2011) Heart rate-associated mechanical stress impairs carotid but not cerebral artery compliance in dyslipidemic atherosclerotic mice. Am J Physiol Heart Circ Physiol 301:H2081-2092

50. Cruz Rodriguez JB, Alkhateeb H (2020) Beta-blockers, calcium channel blockers, and mortality in stable coronary artery disease. Curr Cardiol Rep 22:12

51. Kjekshus JK (1986) Importance of heart rate in determining betablocker efficacy in acute and long-term acute myocardial infarction intervention trials. Am J Cardiol 57:43F-49F

52. Fox K, Ford I, Steg PG, Tendera M, Robertson M, Ferrari R, Investigators B (2009) Relationship between ivabradine treatment and cardiovascular outcomes in patients with stable coronary artery disease and left ventricular systolic dysfunction with limiting angina: a subgroup analysis of the randomized, controlled BEAUTIFUL trial. Eur Heart J 30:2337-2345

53. Meguro K, Kasai M, Akanuma K, Meguro M, Ishii H, Yamaguchi S (2014) Donepezil and life expectancy in Alzheimer's disease: a retrospective analysis in the Tajiri Project. BMC Neurol 14:83

54. Secnik J, Schwertner E, Alvarsson M, Hammar N, Fastbom J, Winblad B, Garcia-Ptacek S, Religa D, Eriksdotter M (2020) Cholinesterase inhibitors in patients with diabetes mellitus and dementia: an open-cohort study of $\sim 23000$ patients from the Swedish Dementia Registry. BMJ Open Diabetes Res Care 8

55. Isik AT, Soysal P, Stubbs B, Solmi M, Basso C, Maggi S, Schofield P, Veronese N, Mueller C (2018) Cardiovascular outcomes of cholinesterase inhibitors in individuals with dementia: a metaanalysis and systematic review. J Am Geriatr Soc 66:1805-1811 